\title{
THE HEART IN THE PNEUMOCONIOSIS OF COALMINERS
}

\author{
BY \\ ARTHUR J. THOMAS \\ From Llandough Hospital, Cardiff \\ Received September 6, 1948
}

The pneumoconiosis of coalminers is a primary disorder of the lungs that can cause pulmonary heart disease, a condition also called cor pulmonale.

The occurrence of right heart changes in pneumoconiosis was noted by Pancoast and Pendergrass (1931). Dyson (1933 and 1934) described the radiological recognition of heart disease in pneumoconiosis, and in a review of 127 cases found 18 with evidence of pulmonary heart disease. Discussing the pathology of pneumoconiosis, Jaffe (1934) concluded that the replacement of large parts of the lungs by poorly vascularized scar tissue, and the occurrence of obliterative changes in the branches of the pulmonary artery, interfered greatly with the pulmonary circulation. Right ventricular hypertrophy followed and failure of the right heart was a common cause of death in advanced pneumoconiosis.

Coggins et al. (1938) found that hypertrophy of the right ventricle was a common finding in the autopsy records of 102 proven cases of pneumoconiosis. Other studies of the pathology of pulmonary heart disease record right ventricular hypertrophy with anthraco-silicosis (Scott and Garvin, 1941; Spain and Handler, 1946). In the South Wales anthracite coalfield, Gooding (1946) has reviewed a series of 227 post-mortem examinations on miners certified as having pneumoconiosis; 37 per cent are described as having died from cardiac failure, usually right-sided.

Emphysema is a common cause of pulmonary heart failure. Gough $(1940,1946,1947)$ has described the occurrence of emphysema in coalminers' pneumoconiosis and has differentiated the focal emphysema from the bullous emphysema that occurs in later stages of the disease. Geever (1947) has confirmed the occurrence of pulmonary vascular changes.

The clinical course of a pulmonary disease may be divided into two phases, the pulmonary phase and the cardiac phase (Brill, 1939). The clinical features of the cardiac phase in pneumoconiosis have teen described by several writers, some of whom have indicated the difficulties in assessing the degree of involvement of the right heart (Coggins et al., 1938; Giering and Charr, 1939; and Ketterer, 1941).

McMichael and Sharpey Schafer (1944) have drawn attention to the fact that cases of cor pulmonale may have a high cardiac output. They have found this in patients with emphysema, gross venous congestion, and a low arterial oxygen saturation. In the terminal stages the left heart may fail and pulmonary œdema occur.

The pneumoconiosis of coalminers has been presented in detail by Fletcher (1948).

\section{Selection of Cases}

The subjects of this investigation have been inpatients under the care of the Pneumoconiosis Research Unit (M.R.C.) at Llandough Hospital. A certain measure of selection has been exercised in this series because of the exclusion of patients with any signs of cardiovascular disease other than that resulting from the pulmonary disorder. There are 96 cases of coalminers' pneumoconiosis ranging from the earliest detectable stage to the final stage of advanced disease and right heart failure. Their ages vary from 28 to 65 years, but the severity of the disease is not proportional to the age. For ease of description a clinical grading has been adopted, based on the history, the degree of dyspnœa, and the capability for exertion.

\section{The Clinical Examination}

The symptoms of the pulmonary phase were dyspnœa, fatigue, cough, and intermittent attacks of pain in the chest. The dyspnœa was exertional and slight at first, but usually increasing in severity. Paroxysmal dyspnœea was not uncommon and was not cardiac in origin. A complaint of being easily fatigued was often an early symptom. Cough was present at some stage, sometimes productive in type. The pain in the chest was the result of the pulmonary 
TABLE I

Classification of Cases

\begin{tabular}{|c|c|c|}
\hline & & $\begin{array}{l}\text { No. of } \\
\text { cases }\end{array}$ \\
\hline $\begin{array}{l}\text { Grade I } \\
\text { Grade II } \\
\text { Grade III } \\
\text { Grade IV }\end{array}$ & $\begin{array}{l}\text { Those not definitely disabled } \\
\text { Those with slight disability } \\
\text { Those with moderate disability } \\
\text { Those with serious or complete disability }\end{array}$ & $\begin{array}{l}14 \\
35 \\
15 \\
32\end{array}$ \\
\hline
\end{tabular}

disease although sometimes simulating pain of cardiac origin. The site of the pain in the chest varied from time to time, and its onset was not always related to exertion. The physical signs of the pulmonary phase were similar to those of emphysema and chronic bronchitis without heart disease.

The symptoms of the cardiac phase were severe dyspnœa, gross disability, œdema of the feet and ankles, and upper abdominal discomfort. The patients would often complain only of marked exacerbation of their previous condition.

The physical signs of the cardiac phase were orthopnœa, cyanosis, engorgement of the neck veins, warm hands, œdema of the ankles, tenderness of the palpable liver, a full peripheral pulse of regular rhythm, and triple heart rhythm.

Orthopnoa might be the earliest sign of imminent heart failure and might be related to the history of an exacerbation of the pulmonary phase. Cyanosis was occasionally present with the advanced pulmonary phase but was often a sign of right heart failure. Engorgement of the neck veins was present only when the heart failed; it has not been seen in this series as a result of the pulmonary disorder alone. Warm hands were noted when failure occurred but the sign was less distinctive as failure persisted. CEdema of the feet or ankles appeared as a very early finding and quickly increased to a severe degree. The liver might be palpable in the pulmonary phase owing to the low diaphragm but tenderness was limited to the cardiac phase. The pulse was full and usually of regular rhythm. The blood pressure in all these cases was between 100 and $150 \mathrm{~mm}$. systolic, and 50 and $90 \mathrm{~mm}$. diastolic. The majority had a blood pressure of the order of 110 systolic and 70 diastolic. The heart size and position were difficult to assess. The cardiac impulse was felt in the epigastrium. The heart sounds were distant except at the sternal margins and in the epigastrium. Triple heart rhythm (protodiastolic gallop) was heard to the left of the lower sternum in 75 per cent of the cases when the right heart failed. There was accentuation or splitting of the second sound in the pulmonary area. A systolic murmur of moderate intensity was heard in the mitral area in two cases. Slight sinus tachycardia was evident at complete rest and the rate accelerated with the slightest exertion. One patient was exceptional in having auricular flutter; there were no records of auricular fibrillation. The hæmoglobin levels were within normal limits except in two cases where the readings were below normal. Severe jaundice was noted in one case of severe failure and milder jaundice in another.

Right heart failure was present in 11 cases: in 9 of them it was fatal.

The stage at which right heart involvement first occurred was difficult to detect. One half of those in the pulmonary phase showed a maximal impulse at the lower end of the sternum and had accentuation or splitting of the pulmonary second sound. The splitting of the second sound was often audible down the left border of the sternum. In one instance a short diastolic murmur was audible at the pulmonary area with the breath held in inspiration. The signs found in the pulmonary area can be classed as suggestive of right heart strain. The clinical examination is not very helpful in detecting early right heart involvement.

\section{The Radiological Examination}

The clinical worth of radiology in the study of heart disease has been stressed by Parkinson (1936). The pathological studies of Kirch (1930) on the right ventricle and its inflow and outflow tracts are applicable to this work. Kerley (1931), Schwedell (1946), and many others have described the radioscopic features of right ventricular enlargement.

Enlargement of the right ventricle takes place first in the outflow tract and is seen as a prominence of the pulmonary conus-artery segment. There is straightening of the upper left cardiac border in the anterior view and an anterior bulge reducing the retrosternal space in the right anterior oblique view. Right ventricular inflow tract enlargement is manifested by increasing width and depth of the right ventricle in the anterior and the left anterior oblique views, particularly in the latter. Tomography of the 

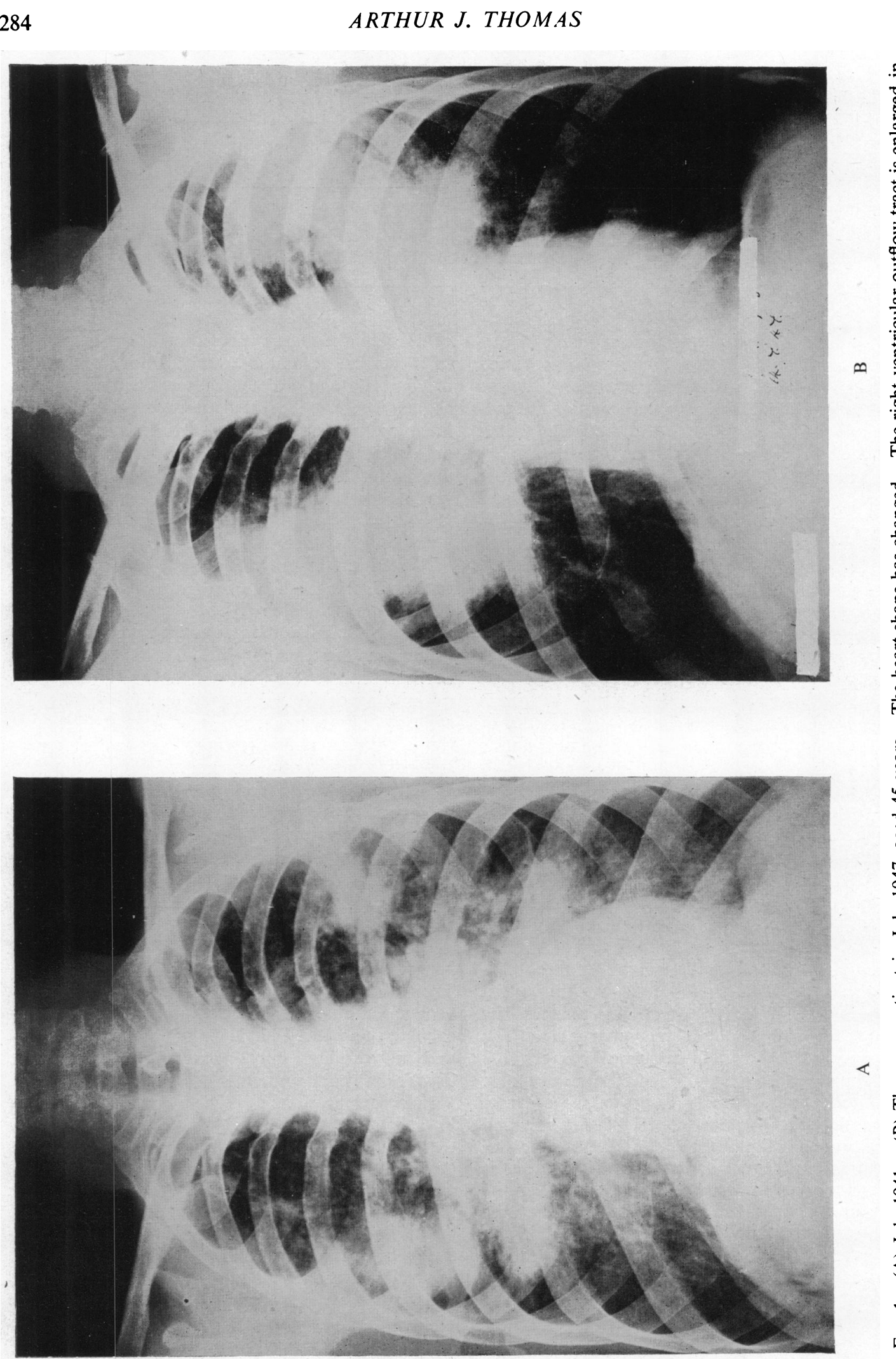

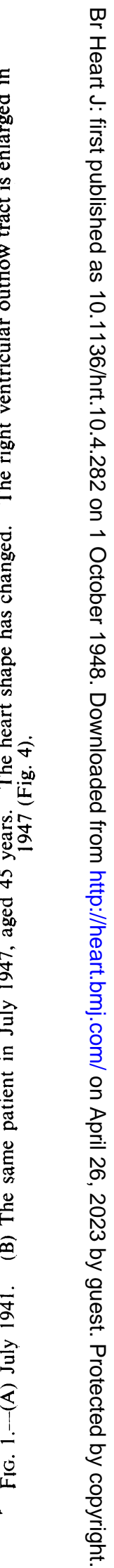



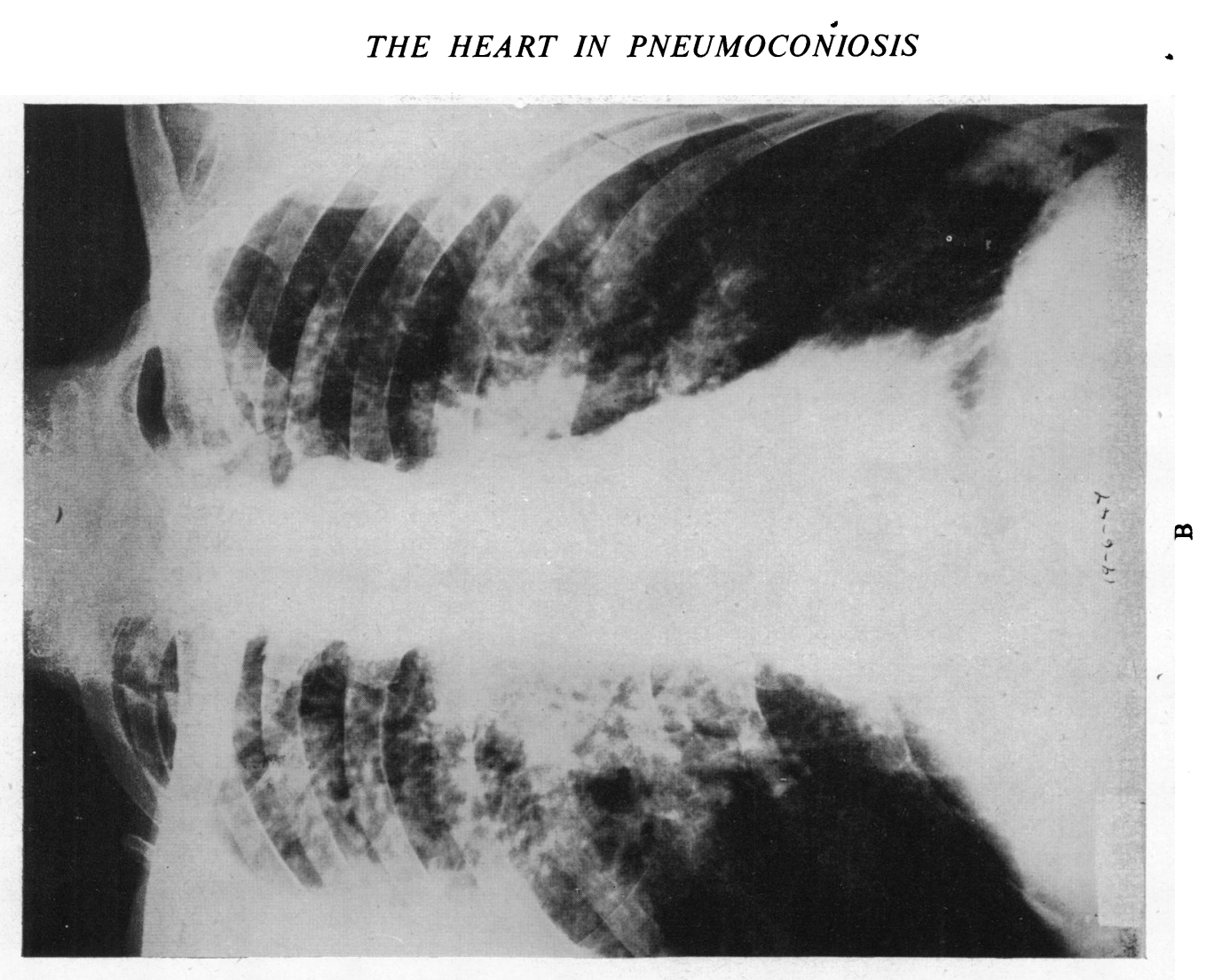

285

믹

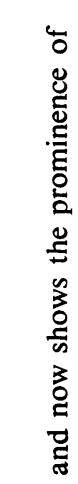

$\infty$

"ृ.ّ

을

สํี

g:

융 군

응

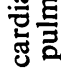

엉

론

象壳

尺ี

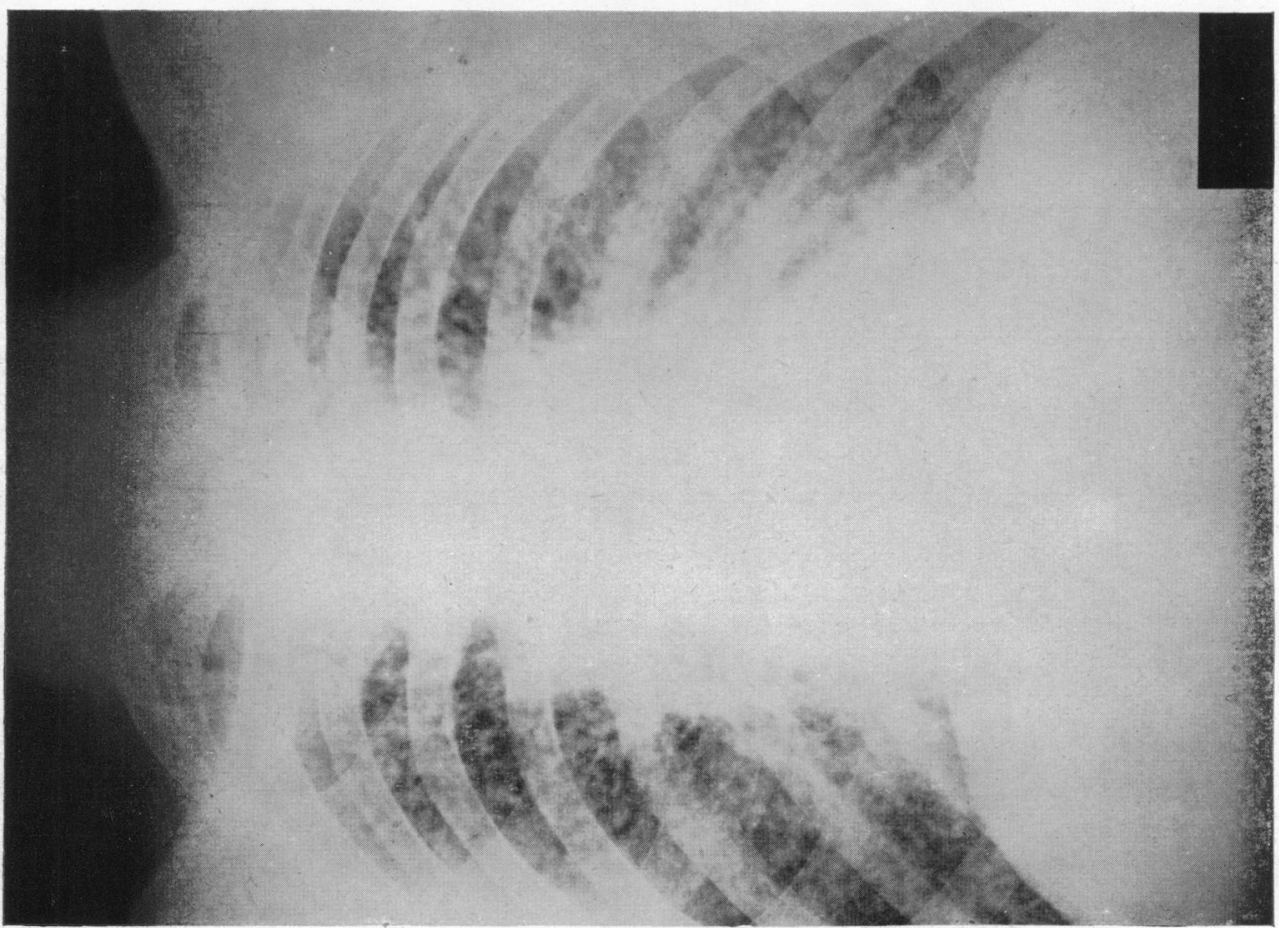


heart shadow in the right anterior oblique view has been found of value in recording enlargement of the right ventricular outflow tract.

Two noteworthy changes occur in the shape of the heart in pneumoconiosis; one is elongation and assumption of a vertical position, the other is enlargement of the outflow tract of the right ventricle.

The general heart shape is analysed in Table II. In ten instances, where previous records are available, analysis proves that marked elongation of the heart shape has occurred; radioscopy now shows that the original heart shape cannot be reformed by any respiratory movement (Fig. 1 and 2). The diaphragm has been depressed to produce the elongation, and in some a further real or apparent elongation is produced by the elevation of the lung hila (see Fig. 5).

Five patients in right heart failure had heart shadows rather wider than is expected (Fig. 3). The belief that widening has occurred due to right ventricular inflow tract enlargement is supported by the demonstration of this enlargement in two cases on radioscopy, and by the measuring of actual widening of the shadow in successive teleradiograms of a third case. Even so, the radiological and pathological size of the hearts of those in failure is small, relative to those with the same degree of heart failure from other cardiovascular diseases.

Enlargement of the pulmonary artery and of the outflow tract is a finding of a major importance. Their detection is not easy when much elongation is present and is even more difficult when there is gross distortion. The incidence of this finding is given in Table II.
Further changes may not be detected in some cases for many years. During this interval the heart usually elongates vertically. The final stage is reached when the inflow tract dilates and right heart failure follows very quickly.

The period of prominence of the outflow tract only is presumably that of increase in pulmonary artery pressure and may be called the stage of right heart strain.

\section{The Electrocardiographic Examination}

The electrocardiographic pattern of right ventricular hypertrophy has been described by Wilson et al. (1930, 1944, 1947) and Myers et al., (1948). The three standard leads are affected by the position of the heart and the examination of præcordial lead tracings is essential in studying the right heart. The presence of right axis deviation in the standard leads accompanied by inversion of T II and T III is not diagnostic of right ventricular hypertrophy, (Myers et al., 1948). In pronounced right ventricular hypertrophy abnormally large $\mathrm{R}$ waves with a late peak, frequently $Q$ waves and inverted $T$ waves, are found in leads from the right side of the præcordium. In leads from the left side of the præcordium $R$ is often smaller than usual and an $\mathbf{S}$ wave persists. The QRS deflections are not usually large, nor is the QRS interval wider than normal.

The standard limb leads have been recorded in all cases in this series. An analysis of the axis deviation is shown in Table III.

The common pattern in the standard lead tracings is that associated with the long vertical heartQRS of small amplitude in lead I, R wave of good
Prominence of the pulmonary conus-artery segment has been detected in 4 cases without elongation of the heart shape or heart failure. The remaining 31 with enlargement of the outflow tract include 11 cases that had signs of right heart failure (Fig. 3, 4 , and 6).

Pulmonary conus-artery enlargement has taken place at a comparatively early stage in 2 cases, and has been found with moderate disability in 9 others. amplitude in leads II and III, and frequently a small $\mathrm{Q}$ wave in leads II and III. Inversion of the $\mathrm{T}$ wave in leads II and III occurs in records from 8 patients, 6 of whom were in clinical grade IV.

A high $P$ wave in lead II has been described in pulmonary heart disease by Winternitz (1935) and others, but there is still doubt as to its true significance. Thirty-two records show a $\mathbf{P}$ wave in lead II of an amplitude between 2 and $3 \mathrm{~mm}$; fourteen 


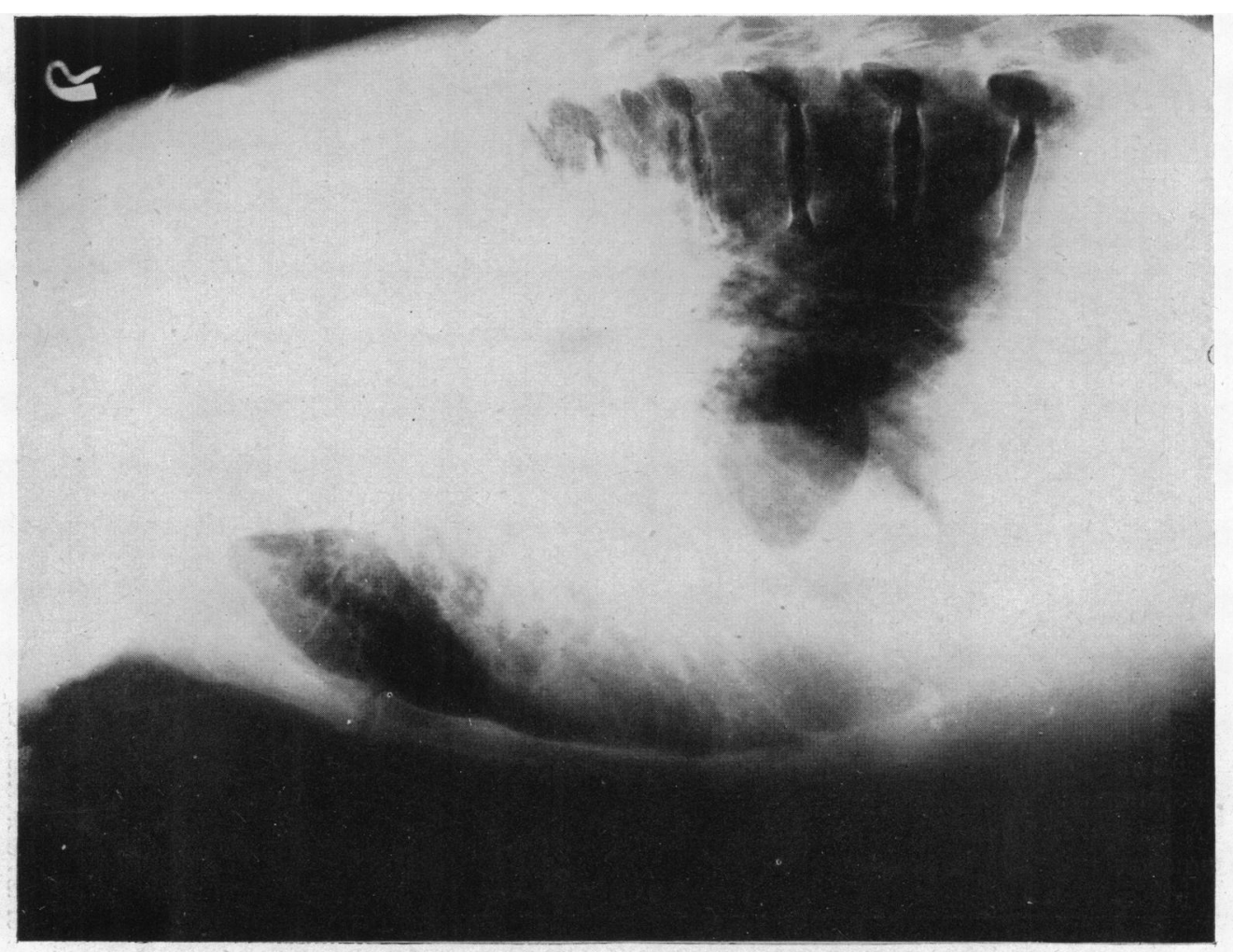

䓕

焉泣

응

苛

ป

몰

.

( )

:

Ф

छํㅗㄹ

范

.

売

은

完

고

可䨌

胥.

\section{d}

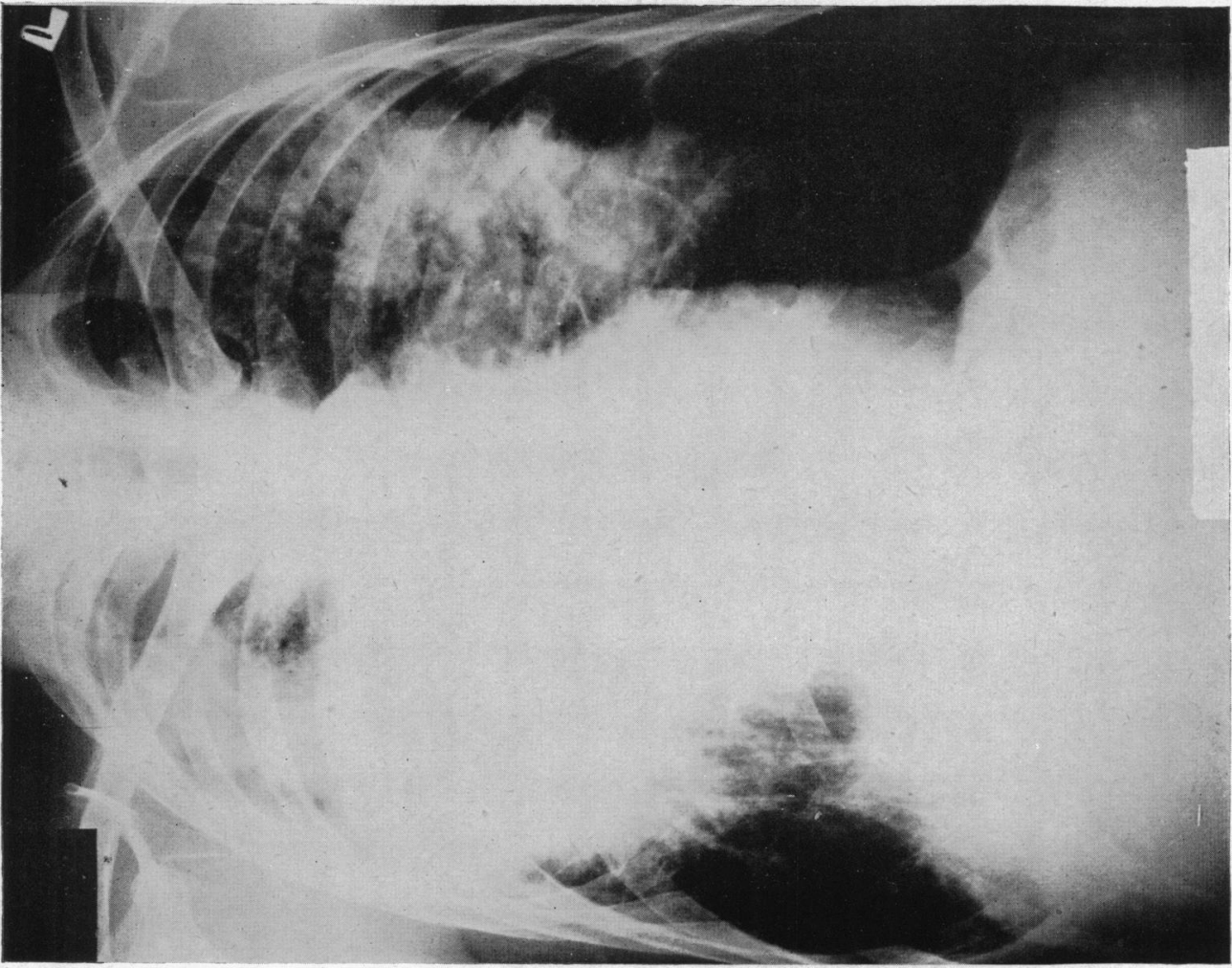

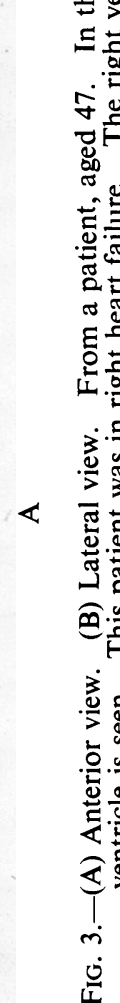

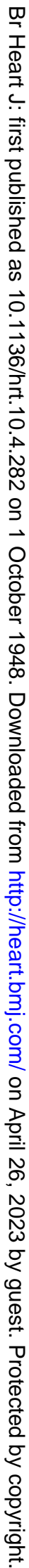



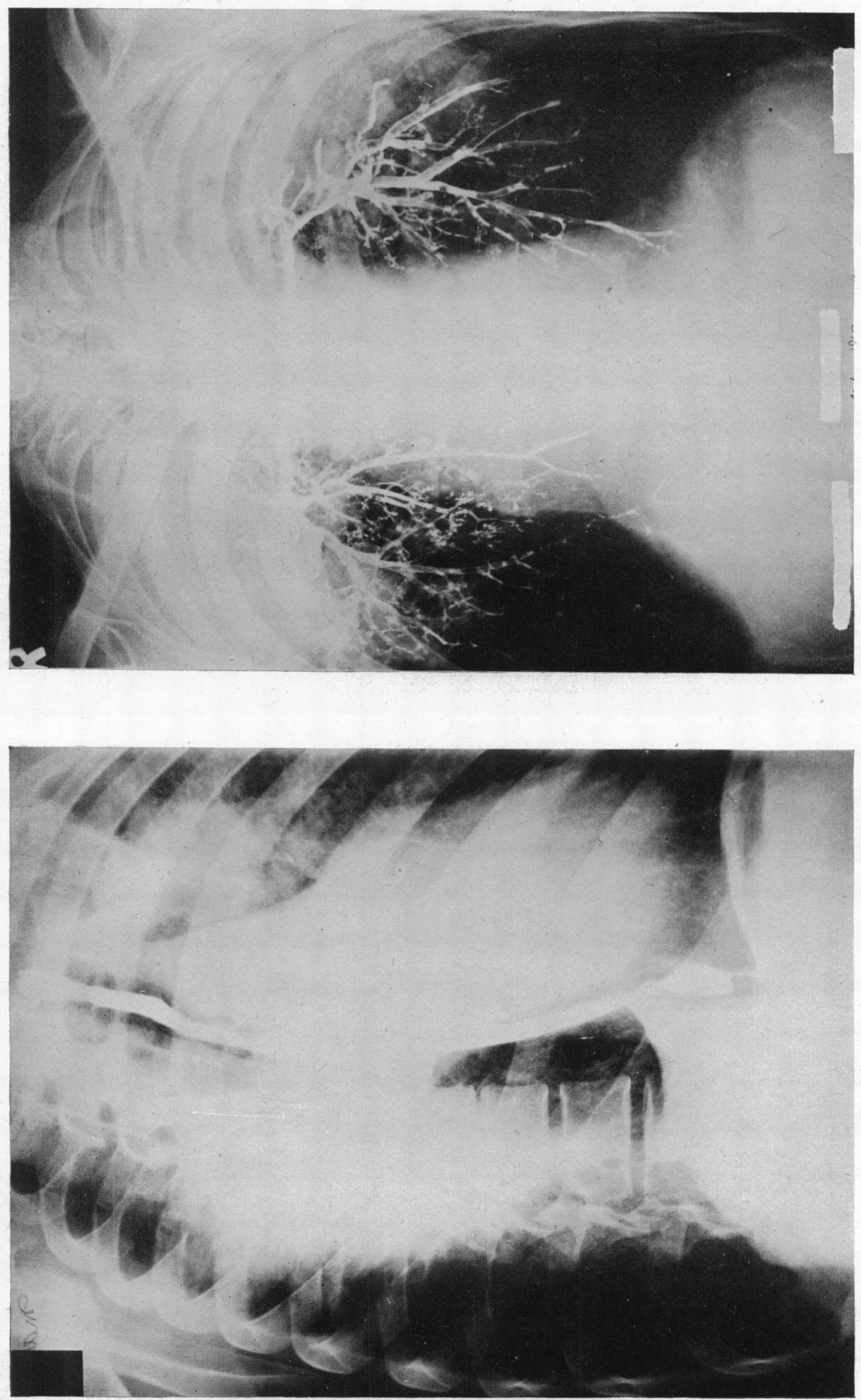

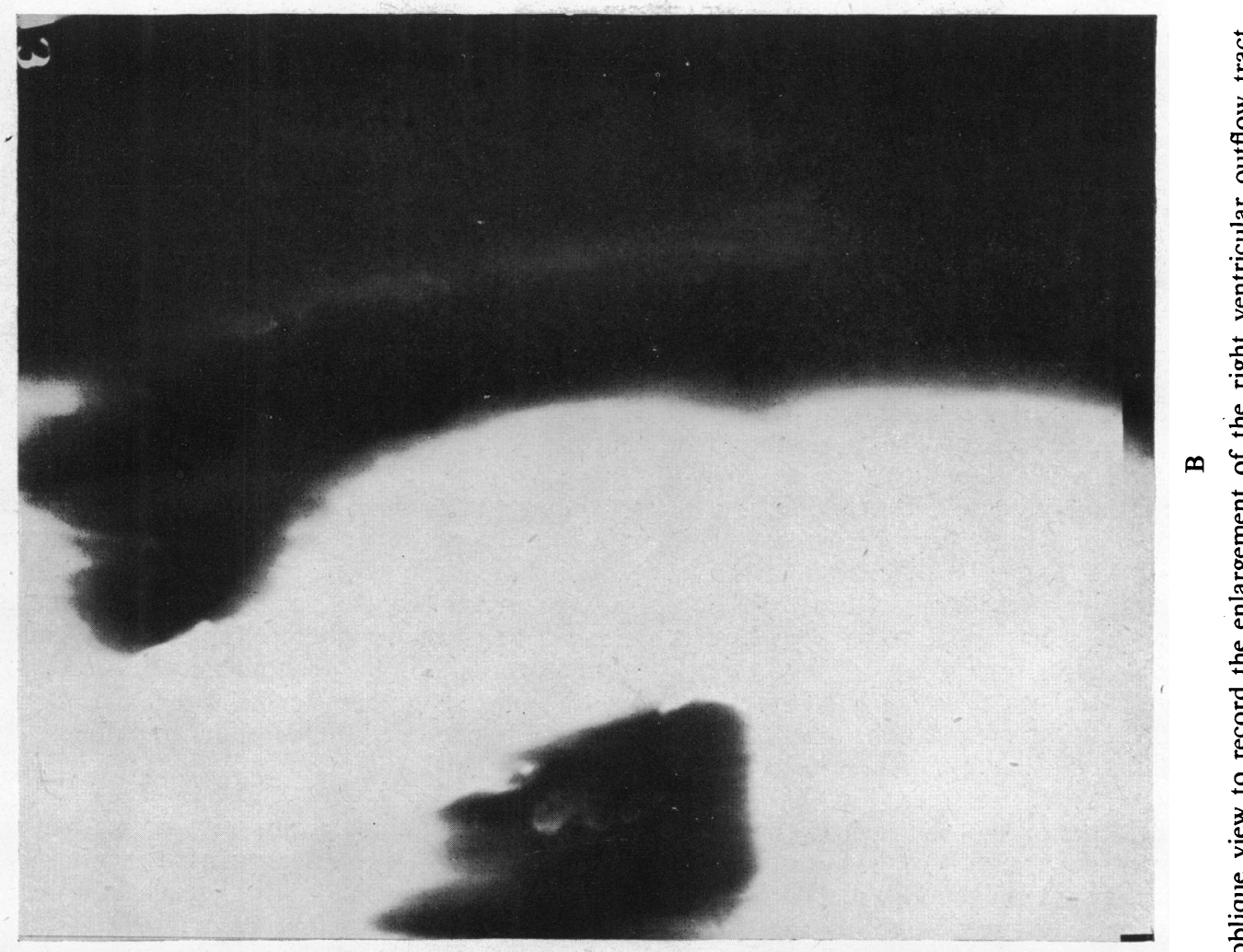

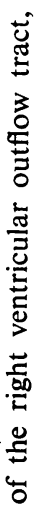
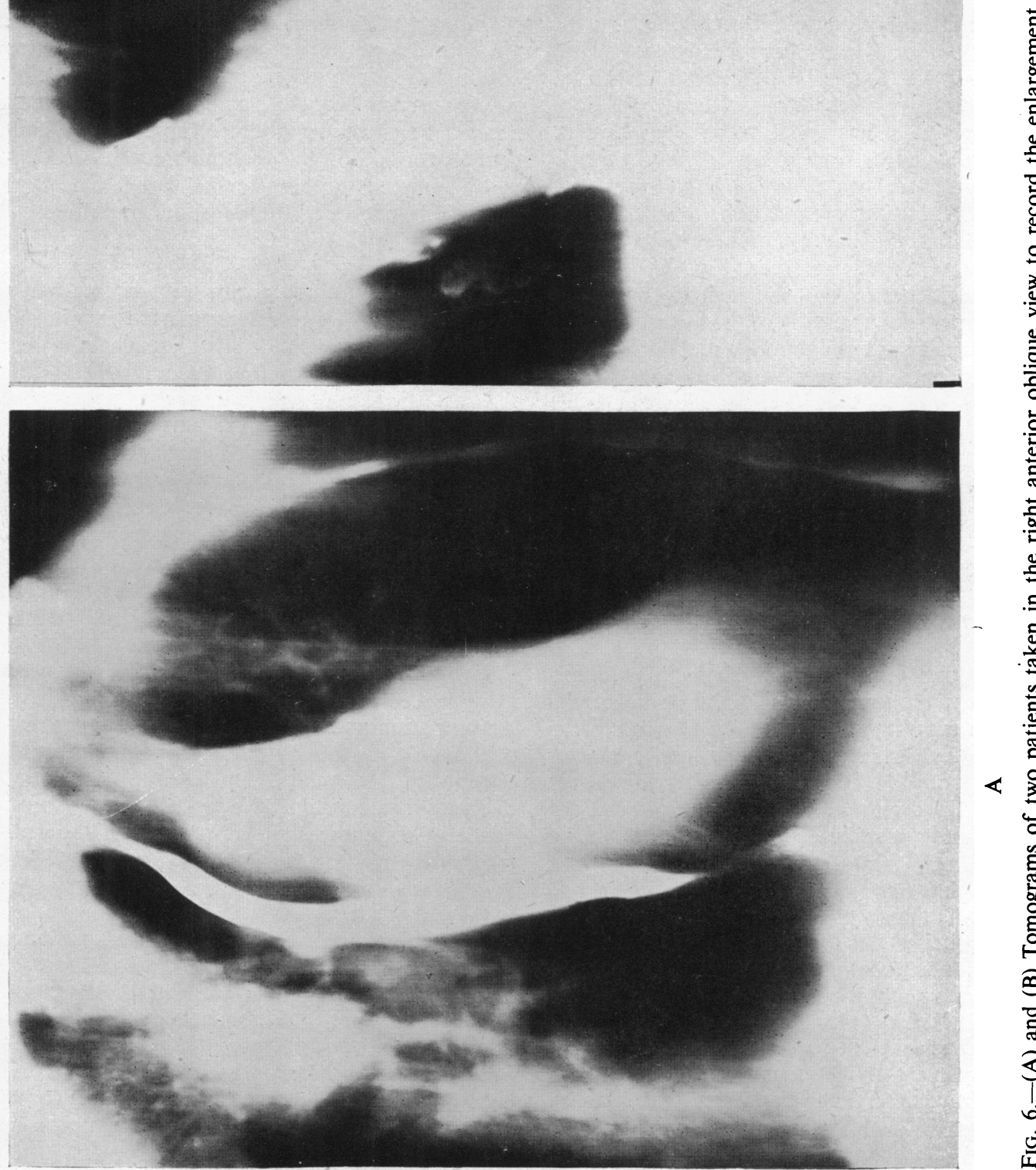

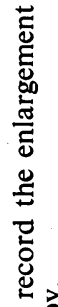

응

.

要

ัํำ

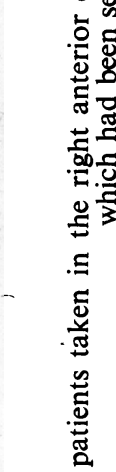

$\ll$

ڤ

¿

है

究

छั

운

อิ

్ㅠ

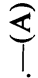

它 
TABLE III

Axis Deviation in Electrocardiograms

\begin{tabular}{c|c|c|c|c}
\hline Axis & $0^{\circ}$ to $+29^{\circ}+30^{\circ}$ to $+59^{\circ}+60^{\circ}$ to $+89^{\circ}+90^{\circ}$ to $+120^{\circ} \begin{array}{c}\text { Over } \\
+120^{\circ}\end{array}$ \\
\hline Cases & 12 & 13 & 40 & 28 \\
\hline
\end{tabular}

have a $P$ wave over $3 \mathrm{~mm}$. amplitude in lead II. The $\mathbf{P}$ wave is abnormally high in these fourteen . cases, ten of whom are in clinical grade IV. It only coincides with other detectable signs of right heart involvement in nine cases. The possibility that rotation of the heart is responsible for the high $P$ wave of lead II cannot be excluded (Fig. 7).

The unipolar limb leads have been recorded in twenty cases. VL has a QS deflection in fifteen, which is indicative of the vertical heart position. VR in five tracings has an $R$ wave suggestive of right ventricular hypertrophy.

Chest leads have been recorded in all cases, CR leads in the first 30 and V leads in the other 66 cases. In eight tracings the pattern of pronounced right ventricular hypertrophy was seen (Fig. 7). All had radiological evidence of right ventricular prominence and post-mortem confirmation of the hypertrophy of the right ventricle has been obtained in three of them.

There is a second group of eight tracings with a distinctive pattern. The QRS complex in leads from the right side (V4R, V3R, V1) is of low amplitude and has a RSR' form; leads from the left side of the præcordium show a persistent $\mathbf{S}$ wave. This pattern is suggestive, but not evidence, of right ventricular hypertrophy (Fig. 7D). Three of these patients had right heart failure and the right heart hypertrophy has been confirmed post-mortem; three others had radiological evidence of right ventricular prominence.

A third group of ten tracings shows a predominantly $S$ wave pattern from the right side of the chest with a small $S$ wave persisting through V4 to V6 (Fig. 7E). The $R$ wave is of normal character in the leads from the left chest. This pattern is not evidence of right ventricular hypertrophy but is of interest because six of these cases were considered to have right heart strain and the right ventricular hypertrophy has been confirmed at autopsy in two of them. It is apparent that rotation has played a part in producing this pattern and the taking of leads from other positions may be of value in confirming the change in the heart.

Twenty-six records thus show abnormality but the classical pattern of ventricular right preponderance is found only in eight. The second chest lead pattern described above deserves to be classed as suggestive of right heart involvement. It is clear that the position of the heart, changed as it may often be in this disease, can modify the chest lead pattern and it is important therefore to take leads from positions further to the right than lead VI and from as far left as V6.

In thirty cases unipolar leads from the right upper abdominal quadrant and from the left upper scapular region have been taken (Goldberger, 1944). The results were not conclusive and heart position again seemed to cause variation. The majority had an upright complex in the abdominal lead, and a downward complex in the scapular lead; a few were diphasic in nature and of very low amplitude.

\section{Conclusions}

Right heart failure occurs in the late stage of pneumoconiosis of coalminers as a result of the pulmonary lesions. When this happens, the clinical picture is the same as that found in heart failure due to other pulmonary diseases; it is true pulmonary heart disease. There is radiological evidence of the right ventricular enlargement and in some cases there is electrocardiographic evidence of right ventricular hypertrophy. Other factors such as rotation of the heart or distortion may mask the typical cardiographic or radiological features.

In the early stages of pneumoconiosis, no evidence of right heart involvement can be detected by the methods used in this investigation.

There are cases in the intermediate stages in whom evidence of right heart strain has been found. Accentuation and splitting of the pulmonary second sound are early signs suggestive of an increase in the tension in the pulmonary artery. Later in the disease it has been possible to demonstrate a prominence of the pulmonary artery and of the outflow tract of the right ventricle. The electrocardiograph has not been as helpful in this group, but has sometimes provided supporting evidence of right ventricular hypertrophy. This right heart strain can persist for a long period, amounting to some years, before the final stage of right heart failure appears. Clearly not more than 50 per cent of the total will develop right heart failure.

The order and frequency of appearance of the signs of right heart strain are only to be expected 


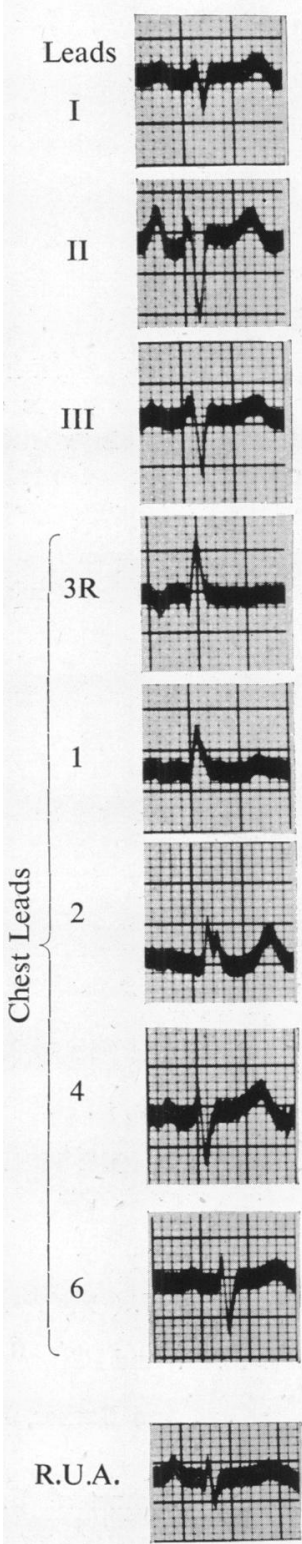

A
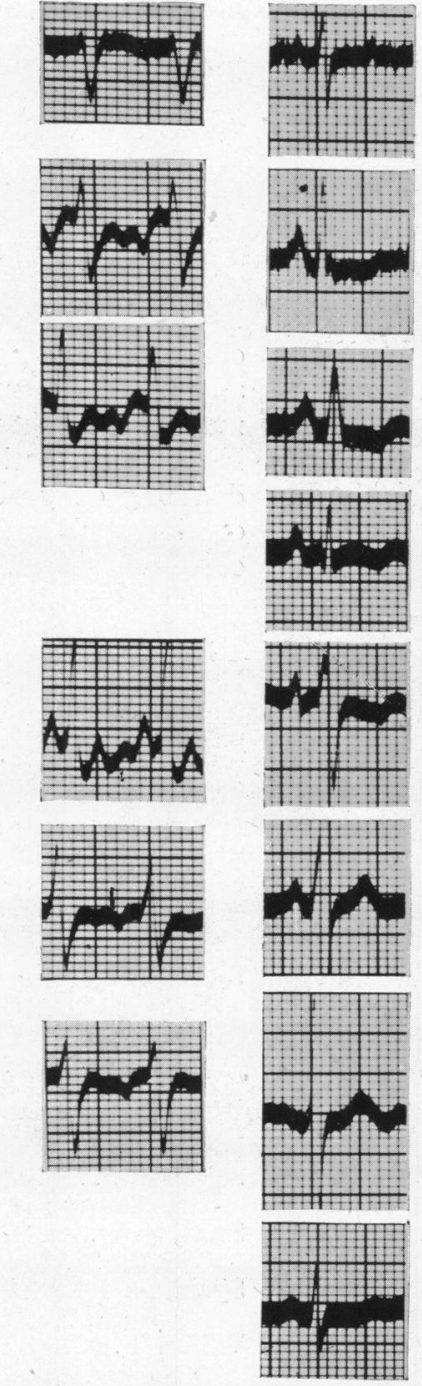

B
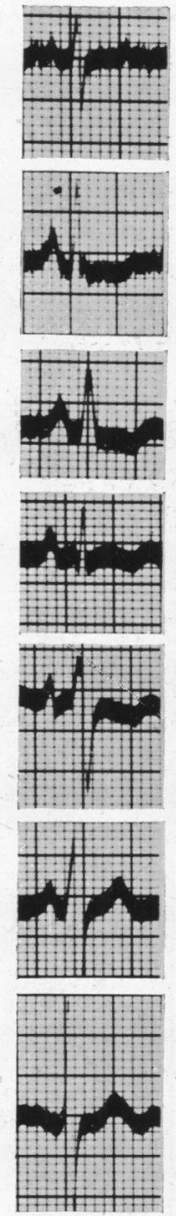
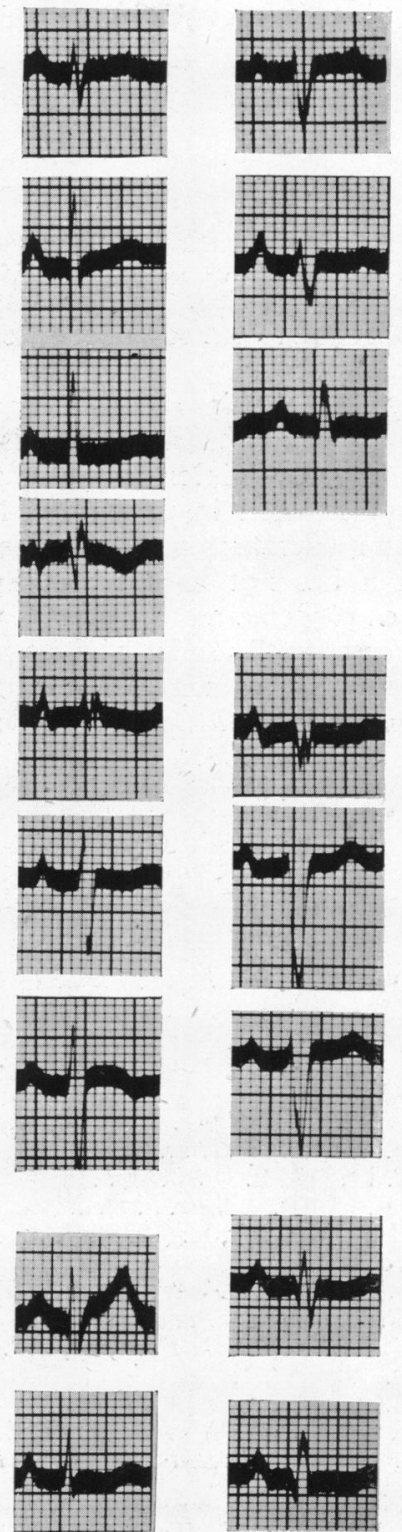

D

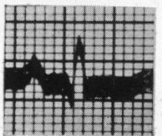

$\mathrm{E}$

Fig. 7.-Cardiograms of five patients with right heart involvement. The chest leads in (B) are CR leads, all others are $\mathrm{V}$ leads.

(A) Clinical grade IV. The pattern is that of right ventricular hypertrophy. This agreed with the other findings.

(B) The pattern is that of right ventricular hypertrophy but auricular flutter is also present. The same case as in Fig. 3.

(C) Right ventricular hypertrophy which was confirmed later, post-mortem.

(D) Clinical and radiological evidence of right heart strain; the pattern is placed in the second group described in the text as suggestive of right heart strain.

(E) The " $S$ " wave chest lead pattern placed in group three in the text, and not taken as evidence of right heart strain. It is probably caused by rotation of the heart. The presence of right ventricular hypertrophy was confirmed later in this case.

R.U.A. is the unipolar lead taken from the right upper abdominal quadrant. 
when it is realized that the initial causation is the change in the dynamics of the pulmonary circulation. Increase in the pulmonary arterial pressure first affects the pulmonary second sound, then dynamic enlargement of the pulmonary artery appears. There follows a dynamic enlargement of the right ventricular outflow tract and it is only when hypertrophy takes place in this tract that the electrocardiographic changes can be expected. The progression is slow but super-added respiratory infections can precipitate the process.

The relating of the signs of right ventricular strain to the pulmonary changes is difficult. Cournand (1947) has drawn attention to the presence of pulmonary hypertension in patients with pulmonary fibrosis and moderate emphysema, when pulmonary hypertension has not been found in those with moderate emphysema alone. Right heart strain is present in cases in this series without severe bullous emphysema but, as shown by Gough, focal emphysema, fine radiating fibrosis, and pulmonary vascular changes may be present. The clinical disability of such cases is only moderate in degree, but the findings in this investigation suggest that pulmonary hypertension is already present. A closer investigation of the respiratory functions of patients with early right ventricular strain may help to elucidate the factors involved in the causation of pulmonary hypertension.

\section{SUMMARY}

A clinical study of the cardiovascular system has been made in 96 patients with pneumoconiosis of coalminers. Eleven patients had right heart failure and another twenty-four had evidence of enlargement of the right ventricular outflow tract. Radiological examination has been of most value in detecting early right heart involvement. Electrocardiographic examination has been helpful in some cases, and the cardiographic patterns are described.

I wish to thank Dr. C. M. Fletcher, Director of the Pneumoconiosis Research Unit (M.R.C.) for permission to study the cases under his care and for access to the records of these cases. A part of this work was incorporated in a Thesis accepted by the University of Wales in 1947.

\section{REFERENCES}

Brill, I. C. (1939). Ann. intern. Med., 13, 513.

Coggin, C. B., Griggs, D. E., and Stilson, W. L. (1938). Amer. Heart J., 16, 411. Cournand, A. (1947). Bull. N. Y. Acad. Med.,

Dyson, J. M. (1933). Amer. J. med. Sci., 186, 165.

Fletcher, C. M. (1948). Brit. med. J., 1, 1015, 1065.

Geever, E. F. (1947), Amer. J. med. Sci., 214, 292.

Giering, J. F., and Charr, R. (1939). J. Amer. med. Ass., $113,574$.

Goldberger, E. (1944). Amer. Heart J., 28, 621.

Gooding, C. G. (1946). Lancet, 2, 891.

Gough, J. (1940). J. Path. Bact., 51, 277.

(1946). Lancet, 1, 462.

- (1947). Occup. Med., 4, 86.

Jaffe, R. H. (1934). Illinois med. J., 66, 431.

Kerley, P. (1931). Recent Advances in Radiology, London. Ketterer, C. H. (1941). Med. Bull. Veterans' Adm.,

Kirch, E. (1930). Klin. Wschr. Berl., 9, 769.
McMichael, J., and Sharpey Schafer, E. P. (1944). Quart. J. Med., 13, 123.

Myers, G. B., Klein, H. A., and Stofer, B. E. (1948). Amer. Heart J., 35, 1.

Pancoast, H. K., and Pendergrass, E. P. (1931). Amer. J. Roentgenol., 26, 556.

Parkinson, J. (1936). Lancet, 1, 1337, 1391.

Schwedell, J. B. (1946). Clinical Roentgenology of the Heart, p. 103, Ann. Roentgenol., New York.

Scott, R. W., and Garvin, C. F. (1941). Amer. Heart J., $22,56$.

Spain, D. M., and Handler, B. J. (1946). Arch. intern. Med., 77, 37.

Wilson, F. N., Macleod A. G., and Barker P. S. (1930). Amer. Heart J., 6, 637.

,$- \frac{1}{1}$, Johnston, F. D., and Barker, P. S. (1933). Ibid., 9, 447. et al. (1944). Ibid., 27, 19.

—, Rosenbaun, F. F., and Johnston, F. D. (1947). Advances in Internal Medicine, 2, 37.

Winternitz, M. (1935). Med. Klin., 31, 1575. 